\title{
Simulative Investigation of FSO System using 4X4 Transmitter Receiver Combination Integrated with Various Types of Amplifiers under Different Weather Conditions
}

\author{
Harneet Kaur ${ }^{1}$ and Himali Sarangal ${ }^{1}$ \\ ${ }^{1}$ Guru Nanak Dev University \\ Harneet.kaur_91@yahoo.com
}

\begin{abstract}
Due to growing demand for wireless broadband communication and congestion on bandwidth of RF spectrum, optical wireless has received considerable attention in the communication world. Optical wireless or free space optics is a good alternative solution to existing RF communication system. The quality of FSO transmission is characterized by BER. Performance degradation faced by the FSO system can be mitigated by using spatial diversity techniques. This work focuses on performance analysis of $4 X 4$ multiple transmitter/receiver combination which is integrated with different types of amplifiers. By using the feasible system parameters for $4 X 4$ multiple transceiver FSO system integrated with preamplification, maximum range of $425 \mathrm{~km}$ can be achieved for acceptable received power under clear weather condition.
\end{abstract}

Keywords: Optical Wireless, Free space optic, Optical amplification, Multiple TX/RX FSO, bit error rate (BER), Preamplifiers

\section{Introduction}

With growth of internet traffic in conjunction with increase in number and range of new services has led to the emergence of free space optics technology which has combined features of wireless and fiber optics .It is also called open air photonics or fibreless optics. It is the transmission of modulated visible or infrared beam through atmosphere to obtain broadband communication. [1] Mostly laser beam, LED's, IRED's (IR emitting LED) are used. Free space optics provide a higher bandwidth to end users at faster speed. Unlike radio frequency it does not require spectrum license. The most important advantages of using FSO are high bit rate, low bit error rate, easy to install and immunity to electromagnetic interference. [2] FSO systems are used for LAN to LAN connections for campuses and cities, crossing public roads and temporary network connections for disaster recovery areas. Inter and Intra chip communication are also the major applications. [3]

This technology is cost effective, secure and provide data rate up to tens of Gbps. [4] Despite of many advantages, FSO system suffers from various limitations which degrade the system performance. Various types of weather conditions such as fog, haze and rain leads to atmospheric attenuation and is wavelength dependent.[5-6] In this work, $1550 \mathrm{~nm}$ is used as it offers lesser attenuation than $850 \mathrm{~nm}$.FSO system also suffers from atmospheric turbulence which further leads to scintillation.[7] This turbulence creates air pockets with different refractive indices which further leads to diffraction, fading and refraction of light beam.[8]FSO system can work for several kilometers as long as there is line of sight communication .Hence it is also effected by obstructions such as birds and cranes etc. Solar interference, building sway, pointing errors and beam divergence are also the major challenges faced by the system [9-10]. 
To overcome the problem of pointing errors, auto tracking systems can be used [11]. Turbulence effect can be mitigated by the multiple beam concept. [12] By using multiple transceiver which is also known as spatial diversity, the FSO system performance can be improved. By doubling the TX/RX combination the received power at the receiver is improved and thus the maximum achievable distance and BER is also improved. [13] The amplifier is applied at the transmitter thus known as the preamplification. Transmission distance and BER performance for system is analyzed based on simulations Preamplification improves the link performance .Three types of amplifiers used are travelling wave amplifier (TWA), Erbium doped fiber amplifier (EDFA) and optical amplifiers. Section 2 describes the simulation set up and system parameters. The Section 3 discusses the results and the paper is concluded in the Section 4.

\section{Simulation Setup}

The software platform uses optical communication package optisystem 7.0 of Optiwave Company. The study establishes a 20Gbps high speed free space optics model based on multiple transceivers integrated with optical amplification. Figure 1 shows the block diagram for the FSO system with 4TX and 4RX combination integrated with different types of preamplifiers. An optical transmitter is connected to a fork, which is a component used to duplicate the number of output ports so that each of the signals coming out from fork's output has the same value with the output signal from the previous component connected to it .The first fork produces the multiple beam and this fork is connected to another set of forks which also produces multiple laser beams.These laser beams are combined by the power combiner. An amplifier is applied before output is given to FSO channel. This can be travelling wave amplifier, EDFA or the optical amplifier chosen from the component library of optisystem. At the receiver side power coming from the FSO channels is again combined by power combiner and then fed to the optical receiver. [13]The three visualizers are used in simulation is the optical power meter, optical spectrum analyzer and BER analyzer.BER analyzer automatically calculates the bit error rate and shows the eye diagram. Comparative performance analysis is done on FSO system for three different preamplifiers under different weather conditions. Table 1 shows the attenuation offered by various weather conditions to 1550 nm wavelength. Table 2 shows the various system parameters.

Table 1. Atmospheric Attenuation at Different Weather Conditions for 1550 nm Wavelength

\begin{tabular}{|l|l|l|}
\hline Weather Conditions & Visibility $\mathbf{( k m )}$ & Attenuation(dB/Km) \\
\hline Clear air & 23 & 0.1 \\
\hline Haze & 2 & 4.2 \\
\hline Light Fog & 0.8 & 15.5 \\
\hline Moderate Fog & 0.6 & 25.5 \\
\hline
\end{tabular}

Table 2. FSO System Parameters

\begin{tabular}{|l|l|}
\hline Parameter & Value \\
\hline Transmitted Wavelength & $1550 \mathrm{~nm}$ \\
\hline Data Rate & $20 \mathrm{Gbps}$ \\
\hline Transmitter Aperture & $2.5 \mathrm{~cm}$ \\
\hline Receiver Aperture & $45 \mathrm{~cm}$ \\
\hline Transmitted Power & $28 \mathrm{dBm}$ \\
\hline APD Responsivity & $52 \mathrm{~A} / \mathrm{W}$ \\
\hline Amplifier Gain & $30 \mathrm{~dB}$ \\
\hline
\end{tabular}




\begin{tabular}{|l|l|}
\hline Transmitter loss & $1.8 \mathrm{~dB}$ \\
\hline Receiver loss & $1.8 \mathrm{~dB}$ \\
\hline Receiver Sensitivity & $-45 \mathrm{dBm}$ \\
\hline Beam Divergence & $2 \mathrm{mrad}$ \\
\hline
\end{tabular}

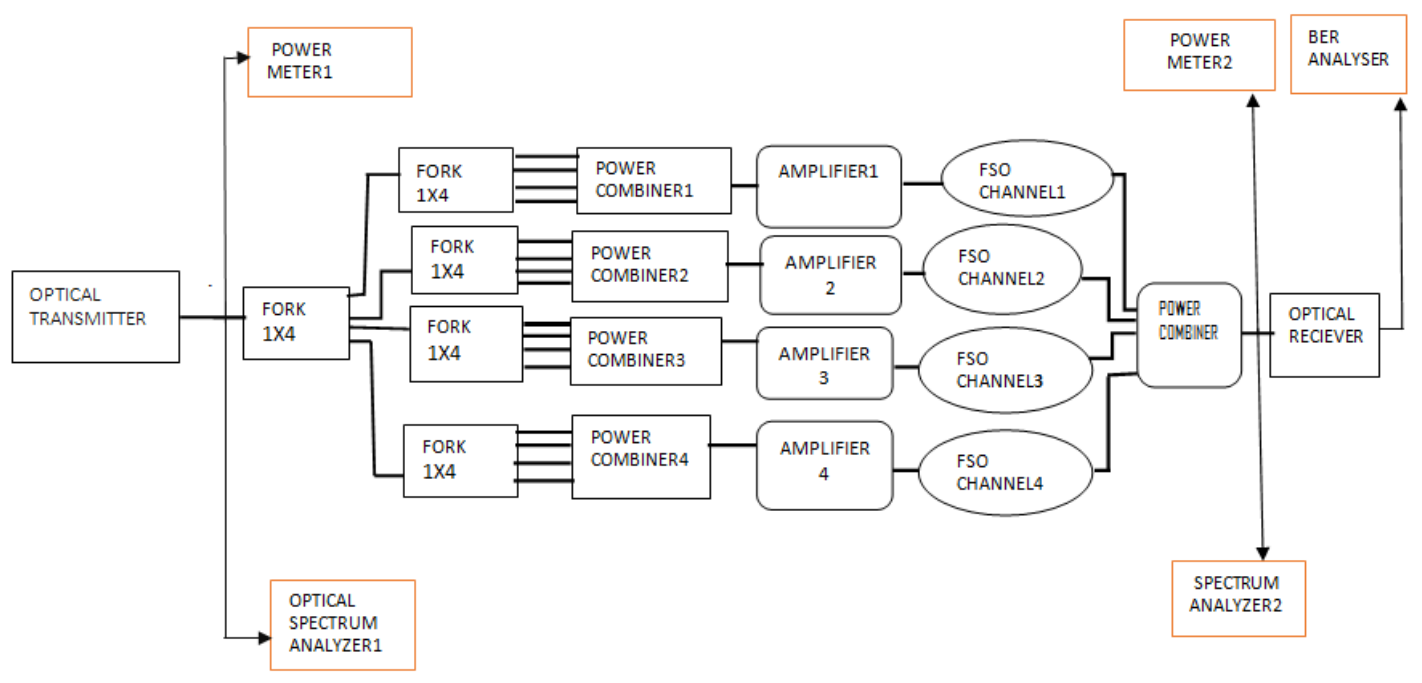

Figure 1. Block Diagram of the FSO System

\section{Results and Discussion}

Multiple TX/RX FSO link is simulated in the optisystem using different types of preamplifiers. Different weather conditions such as fog haze and rain severely effects the system performance. Maximum range which can be transmitted at minimum BER is increased by using optical amplification. Under clear weather conditions, the maximum range of $425 \mathrm{~km}$ and BER of $1.15 \mathrm{e}^{-011}$ can be achieved for $4 \mathrm{X} 4$ multiple transceiver FSO link using optical preamplifiers with acceptable received power. For travelling wave amplifiers and EDFA, the maximum range achieved for clear weather condition is $194 \mathrm{~km}$ and $200 \mathrm{~km}$ respectively. As the attenuation increases with the change of weather condition, the maximum range with acceptable received power also decreases. The FSO system using optical amplifiers shows the good performance than systems using TWA and EDFA as the maximum range is quite high for optical amplifiers. Table 3, Table 4 and Table 5 shows the performance analysis of multiple transceiver FSO link with different preamplifiers for different weather conditions. Figure 2, Figure 3 and Figure 4 shows the graph for BER versus range for different preamplifiers, under clear weather condition applied with the 4X4 multiple transceiver system.

Table 3. Results for Optical Amplifier at Different Weather Conditions

\begin{tabular}{|l|l|l|l|}
\hline Weather Condition & Maximum Range & Received Power & Received BER \\
\hline Clear Air & $425 \mathrm{~km}$ & $-44.23 \mathrm{dBm}$ & $1.15 \mathrm{e}^{-011}$ \\
\hline Haze & $17 \mathrm{~km}$ & $-44.95 \mathrm{dBm}$ & $9.93 \mathrm{e}^{-009}$ \\
\hline Light Fog & $5.25 \mathrm{~km}$ & $-44.95 \mathrm{dBm}$ & $2.54 \mathrm{e}^{-009}$ \\
\hline Moderate Fog & $3.25 \mathrm{~km}$ & $-45.1 \mathrm{dBm}$ & $7.00 \mathrm{e}^{-009}$ \\
\hline
\end{tabular}


Table 4. Results for TWA Amplifier at Different Weather Conditions

\begin{tabular}{|l|l|l|l|}
\hline Weather Condition & Maximum Range & Received Power & Received BER \\
\hline Clear Air & $194 \mathrm{~km}$ & $-43.97 \mathrm{dBm}$ & $2.28 \mathrm{e}^{-010}$ \\
\hline Haze & $10.6 \mathrm{~km}$ & $-43.81 \mathrm{dBm}$ & $1.010 \mathrm{e}^{-010}$ \\
\hline Light Fog & $3.5 \mathrm{~km}$ & $-43.9 \mathrm{dBm}$ & $2.317 \mathrm{e}^{-010}$ \\
\hline Moderate Fog & $2.27 \mathrm{~km}$ & $-43.83 \mathrm{dBm}$ & $1.134 \mathrm{e}^{-010}$ \\
\hline
\end{tabular}

Table 5. Results for EDFA Amplifier at Different Weather Conditions

\begin{tabular}{|l|l|l|l|}
\hline Weather Condition & Maximum Range & Received Power & Received BER \\
\hline Clear Air & $200 \mathrm{~km}$ & $-45.008 \mathrm{dBm}$ & $3.28 \mathrm{e}^{-009}$ \\
\hline Haze & $10.8 \mathrm{~km}$ & $-45.023 \mathrm{dBm}$ & $3.67 \mathrm{e}^{-009}$ \\
\hline Light Fog & $3.55 \mathrm{~km}$ & $-45.045 \mathrm{dBm}$ & $4.21 \mathrm{e}^{-009}$ \\
\hline Moderate Fog & $2.3 \mathrm{~km}$ & $-44.9 \mathrm{dBm}$ & $1.82 \mathrm{e}^{-009}$ \\
\hline
\end{tabular}

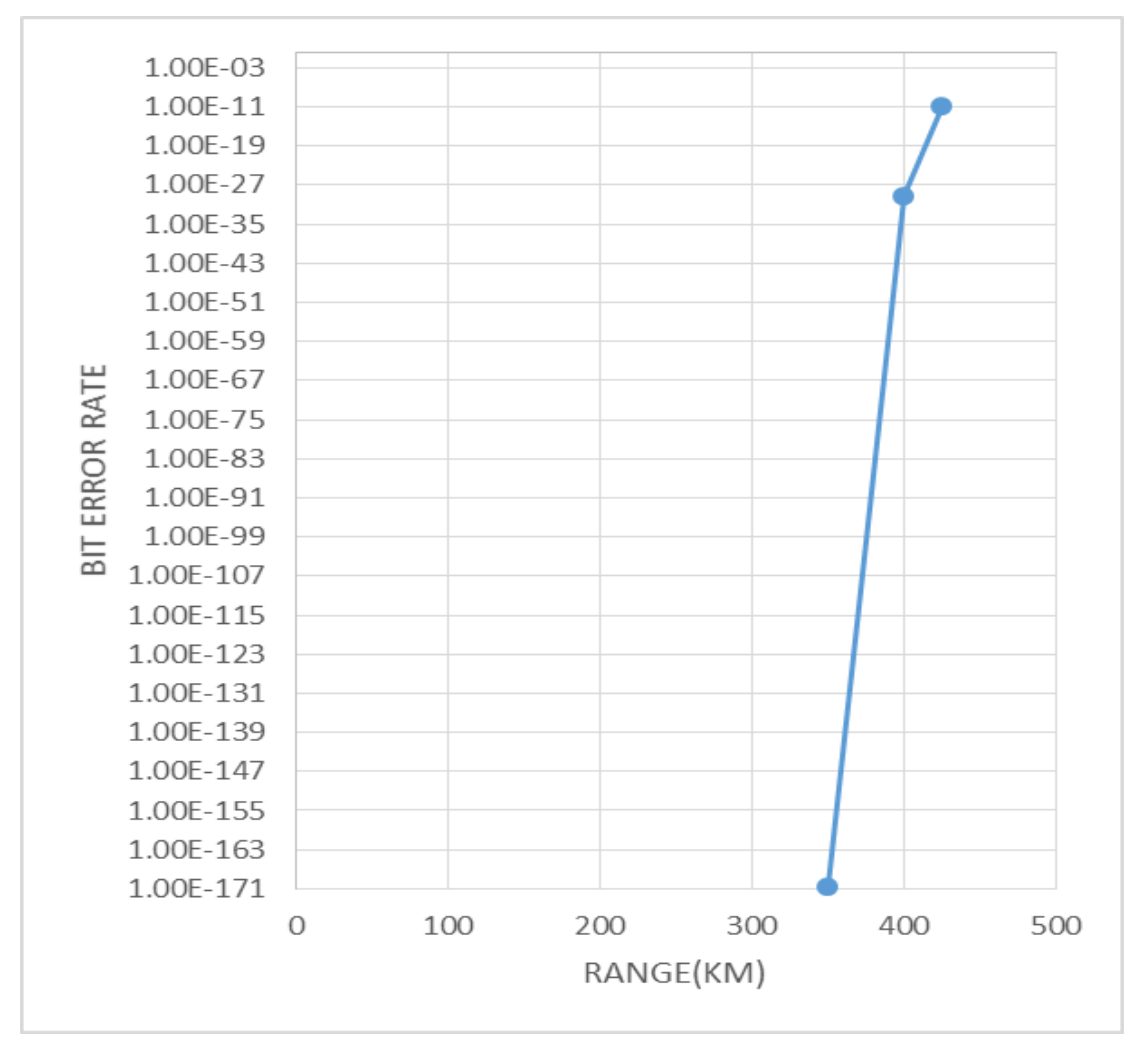

Figure 2. Graph for FSO System with Optical Amplifier 


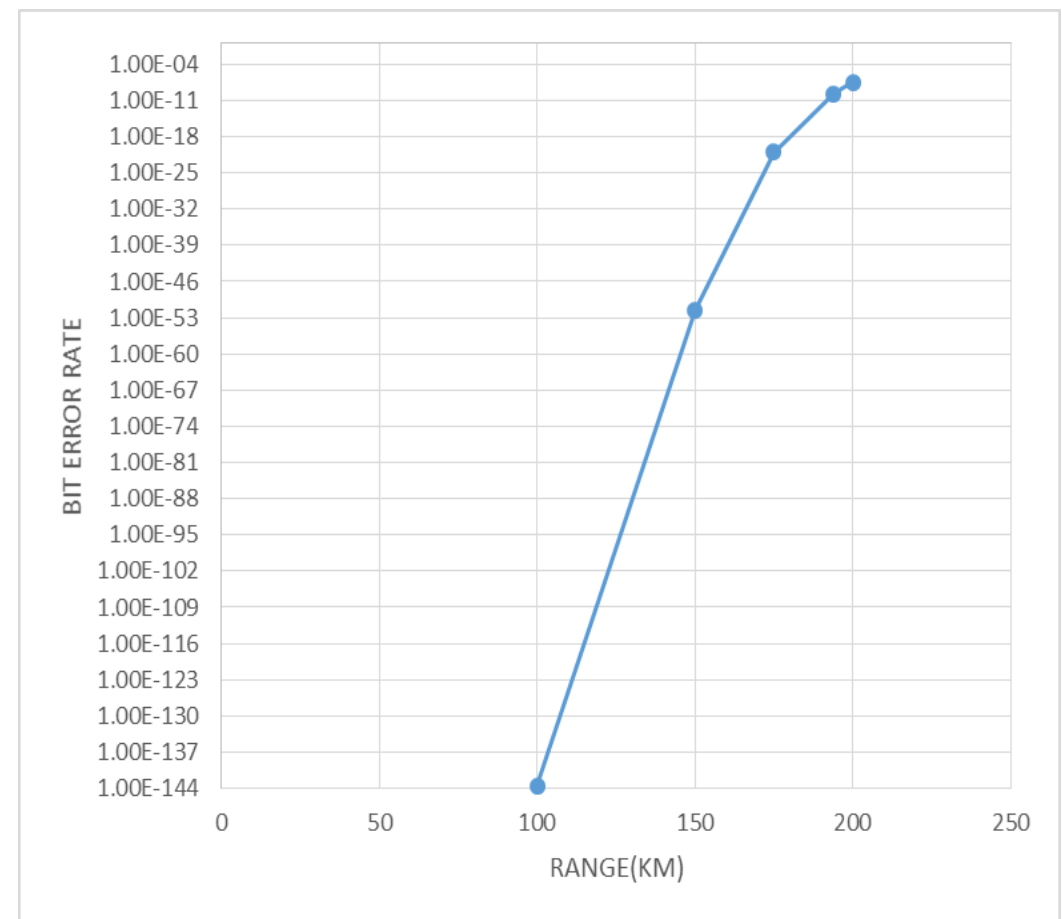

Figure 3. Graph for FSO System with Travelling Wave SOA

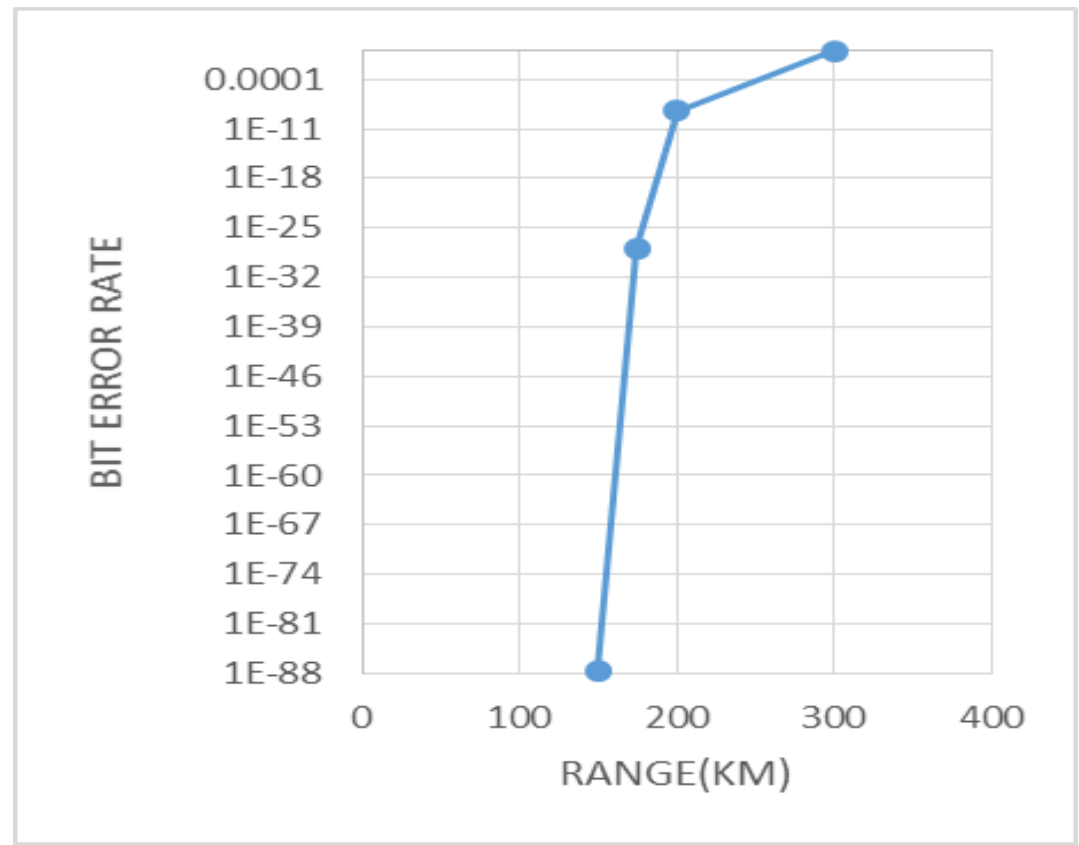

Figure 4. Graph for FSO System with EDFA

\section{Conclusion}

Different weather conditions is the major problem to operate FSO link such as fog, haze and rain. So in this work, a spatial diversity based FSO system is designed that is integrated with different types of preamplifiers which are chosen from component library of optisysem. It is concluded that with the use of multiple transceivers and optical 
preamplifier along with APD receiver, FSO system can work up to $425 \mathrm{~km}$ with acceptable received power and BER under clear weather condition. For EDFA and TWA this range is $200 \mathrm{~km}$ and $194 \mathrm{~km}$ respectively. With the increase of atmospheric attenuation as the weather condition gets worsen, the maximum achieved distance can be extended up to $3.25 \mathrm{~km}$ and $2.27 \mathrm{~km}$ for optical preamplifier and travelling wave preamplifier respectively with acceptable received power and BER. So optical amplifier shows the better link performance as compared with EDFA and TWA because the maximum achievable distance is quite high and BER performance is better.

\section{Acknowledgements}

The authors would like to thank Guru Nanak Dev University (GNDU) for providing us with optisystem software.

\section{References}

[1] S. Bloom, E. Korevaar, J. Schuster and H. Willebrand, "Understanding the performance of free-space optics", Journal of optical networking, vol. 2, no. 6, (2003).

[2] S. Chaudhary, A. Amphawan and K. Nisar, "Realization of free space optics with OFDM under atmospheric turbulence", Journal of optic in science direct, (2014).

[3] M. D'Amico, A. Leva and B. Micheli, "Free space optics communication systems: First result from a pilot field -trial in the surrounding area of Milan, Italy", IEEE microwave and wireless component letters, vol. 13, no. 8, (2003).

[4] V. Annovazzi-Lodi, G. Aromataris, M. Benedetti and S. Merlo, "Secure chaotic transmission on a freespace optics data link", IEEE Journal of quantum electronics, vol. 44, no. 11, (2008).

[5] A. Z. Suriza, I. Md Rafiqul, A. K. Wajdi and A. W. Naji, "Proposed parameters of specific rain attenuation prediction for free space optics link operating in tropical region", Science Direct journal of atmospheric and solar terrestrial physics, vol. 94, (2013).

[6] H. A. Fadhil, A. Amphawan and N. Ahmed, "Optimization of free space optics parameters: An optimum solution for bad weather conditions "Science Direct Journal of Optik, vol. 124, (2013).

[7] X. Zhiu and J. M. Fellow, "Free space optical communication through atmospheric turbulence channels", IEEE transactions on communications, vol. 50, no. 8, (2002).

[8] G. K. Rodrigues, V. Gouvea, A. Carneiro, A. Rubin da Cruz and M. T. M. Rocco, "Evaluation of the strong turbulence impact over free space optical links", Science Direct journal on Optics communications, (2013).

[9] N. A. Mohammed, A. S. El-Wakeel* and M. H. Aly, "Performance evaluation of FSO link under NRZRZ line codes, different weather conditions and receiver types in the presence of pointing errors", The Open Electrical \& Electronic Engineering Journal, (2012).

[10] X. Liu, "Free-space optics optimization models for building sway and atmospheric interference using variable wavelength", IEEE transactions of communication, vol. 57, no. 2, (2009).

[11] A. S. El Wakeel and M. H. Aly, "Pointing error in FSO link under different weather conditions", International journal of Video \& Image processing and network security IJVIPNS-IJENS, vol. 12, no. 1.

[12] S. A. Al-Gailani, A. B. Mohammad, R. Q. Shaddad, "Enhancement of free space optical link in heavy rain attenuation using multiple beam concept, "Science Direct journal on optic, vol. 124, (2013).

[13] N. H. M D Noor, A. W. Nazi and W. AL-Khateeb, "Performance Analysis of a free space optics link with with Multiple transmitters/receivers", IIUM Engineering Journal, vol. 13 no. 1, (2012). 